\title{
Outcome of Oligonodular Hepatocellular Carcinoma after Hepatectomy
}

\author{
Hossain SMS ${ }^{1}$, Hasan $\mathrm{MM}^{2}$, Rahman $\mathrm{MM}^{3}$
}

DOI: https://doi.org/10.3329/jafmc.v15i1.48643

\begin{abstract}
Introduction: Hepatocellular carcinoma $(\mathrm{HCC})$ is a common cancer and is the third most common cause of cancer-related death worldwide. Frequent recurrence of HCC after resection is a major surgical limitation. Early recurrence is the most disappointing outcome after surgery for multinodular HCC. Several studies found good results after hepatectomy for oligonodular (2 or 3 nodules) HCC.
\end{abstract}

Objectives: To observe the recurrence rate three months after hepatectomy for oligonodular HCC and study the possible risk factors.

Materials and Methods: The study population consisted of 102 patients with oligonodular HCC and received hepatectomy in Combined Military Hospital (CMH) between July 2011 and July 2017 according to the following criteria: (1) numbers of tumour nodules determined by preoperative imaging (computed tomography or magnetic resonance imaging) and intraoperative exploration; (2) diagnosis of HCC confirmed by postoperative histopathology; (3) incision margins negative; (4) complete clinicopathologic data; (5) adjuvant chemotherapy advised one month after operation. Multicentric occurrence (MO) and intrahepatic metastasis (IM) were determined in each patient according to the histopathologic examination.

Results: Among 102 patients, 43(42.2\%) had small tumor stain three months after surgery, 22(21.6\%) and $21(20.6 \%)$ were definded as single and multiple recurrence respectively. The recurrence rate of patients with microvascular involvement was higher $(64.3 \%)$ than those without $(33.8 \%),(p<0.05)$. IM or MO, complete tumor capsule or not, number of tumors (2 versus 3 ), liver condition (cirrhosis versus chronic hepatitis) showed no significant difference.

Conclusion: There was a high rate of very early recurrence for patients with oligonodular HCC three months ater hepatectomy, and the hepatic resection seems no-account for these patients regardless of very early recurrence or not a curative resection. Microvascular involvement was a risk factor while IM or MO is not.

Key-words: Hepatocellular carcinoma, Oligonodular, Intrahepatic metastasis and Recurrence.

\section{Introduction}

Hepatocellular carcinoma ( $\mathrm{HCC}$ ) is a common cancer and is the third most common cause of cancer-related death worldwide and is particularly prevalent in China ${ }^{1,2}$. With advances in surgical techniques and perioperative care, hepatic resection for $\mathrm{HCC}$ can be performed with a low hospital mortality rate, even in patients with chronic liver disease ${ }^{3,4}$. The results of hepatic resection ${ }^{5.7}$ for early-stage $\mathrm{HCC}$ were favorable with 5 -year survival rates ranging from $40 \%$ to $70 \%$. However, the frequent recurrence of $\mathrm{HCC}$ after resection is a major surgical limitation. Recurrence rates range from $78 \%$ to $96 \%$ and may be the result of intrahepatic metastases (IM) or multicentric occurrence $(\mathrm{MO})^{8}$. The time interval from resection of $\mathrm{HCC}$ to recurrence has been reported to be an independent prognostic factor of survival after recurrence ${ }^{9}$.

The role of resective surgery in patients with multinodular HCC is still under debate, although several studies have declared good results of hepatic resection for patients with two or three nodules ${ }^{10,11}$. Early recurrence is the most disappointing reason, and if patient presents recurrence one month after hepatectomy, the hepatic resection seems no-account. Therefore, in this study, we made an observation of recurrence one month after hepatectomy for oligonodular ( 2 or 3 nodules) HCC.

\section{Materials and Methods}

This interventional study was conducted from July 2011 to July 2017, there were 102 patients with two or three HCC nodules received hepatectomy in our hospital. All the patients had good liver function (Child-Pugh"s class A) and were offered hepatic resection. These 102 patients were enrolled in this study according to the following criteria: (1) number of tumor nodules determined by preoperative imageology (computed tomography or magnetic resonance imaging) and intraoperative exploration; (2) diagnosis of HCC confirmed by postoperative histopathology; (3) incision margins negative; (4) complete clinicopathologic data; Clinicopathologic data from 102 patients were collected. 31 patients were excluded for the following reasons: one patient died after surgery during the first hospital admission for liver resection; and 30 patients did not report for chemotheraoy one month after operation.

The number of tumors were calculated by either main tumor and satellite nodules or separated nodules. When comparing the two or three nodules in each patient, $\mathrm{MO}$ and IM were determined in accordance with conventional histological criteria ${ }^{12}$. Briefly, MO have the following features: (1) each nodule should be separately registered as a principal tumor; (2) separated nodules that consist of early HCC of well differentiated type or that imply tumors of moderately or poorly differentiated HCC that have a margin of

1. Col SM Shakhwat Hossain, MBBS, FCPS, Diploma in Hepatobiliary Surgery (China), Advanced Training in HBPS (Singapore), Classified Specialist in Surgery \& Head of the Department of Hepatobiliary Surgery, CMH, Dhaka (E-mail: shak778@yahoo.com) 2. Lt Col Md Mahboob Hasan, MBBS, FCPS, Diploma in Hepatobiliary Surgery (China), Classified Specialist in Surgery and Hepatobiliary Surgeon, CMH, Dhaka 3. Maj Gen Md Mahbubur Rahman, MBBS, FCPS, Fellow Colorectal Surgery (France), Consultant Surgeon General, Directorate General of Medical Services, Ministry of Defence, Dhaka. 
well differentiated HCC; (3) different subtype of HCC is diagnosed in each nodule. The other tumors not meeting the MO criteria were defined as IM, which mainly have such features: (1) tumors clearly growing from portal vein thrombi; (2) tumors surrounding a large main tumor with multiple satellite nodules; (3) a small solitary tumor near the main tumor that is histologically similar or less differentiated than the main tumor. Data were collected and analyzed with SPSS 13.0. The differences between categorical variables were analyzed with a chi-square test and $p$ values $<0.05$ were considered statistically significant.

\section{Results}

There were 96 males and 6 females, for a male-to-female ratio of 16:1. The median patients' age was 50 years (range 29-75 years). All the patients had viral hepatitis, of which 98 patients had hepatitis B virus (HBV). There were $2 \mathrm{HCC}$ nodules in $84(82.4 \%)$ patients and 3 in 18(17.6) patients. According to the histologic findings, liver cirrhosis was appearanced in 69(67.6\%) patients, median tumor size was $4.0 \mathrm{~cm}$ (rang $0.5-21 \mathrm{~cm}$ ), $28(27.5 \%)$ patients manifestated microvascular involvement, $57(55.9 \%)$ and $45(44.1 \%)$ patients were considered to be IM and $\mathrm{MO}$ respectively (Table-I). A total $43(42.2 \%)$ patients had small tumor stain one month after surgery. 21.6\%(22/102) and $20.6 \%(21 / 102)$ were definded as single and multiple recurrence respectively. The recurrence rate of patients with microvascular involvement was significantly higher than those without microvascular involvement $(64.3 \%$ versus $33.8 \%)$, $(p<0.05)$, while other variables showed no significant difference (Table-II).

Table-l: Clinicopathological features of patients $(n=102)$

\begin{tabular}{|c|c|c|c|}
\hline Variables & & Frequency & Percentage \\
\hline \multirow{2}{*}{ Age } & $<40$ years & 16 & 15.7 \\
\hline & $\geq 40$ years & 86 & 84.3 \\
\hline \multirow{2}{*}{ Gender } & Male & 96 & 94.1 \\
\hline & Female & 6 & 5.9 \\
\hline \multirow{3}{*}{ Hepatitis etiology } & HBV & 98 & 96.0 \\
\hline & $\mathrm{HCV}$ & 2 & 2.0 \\
\hline & HBV\&HCV & 2 & 2.0 \\
\hline \multirow{2}{*}{ Number of tumors } & $2 \mathrm{HCC}$ & 84 & 82.4 \\
\hline & $3 \mathrm{HCC}$ & 18 & 17.6 \\
\hline \multirow{2}{*}{ Serum AFP level } & $\leq 100 \mathrm{ng} / \mathrm{ml}$ & 40 & 39.2 \\
\hline & $>100 \mathrm{ng} / \mathrm{ml}$ & 62 & 60.8 \\
\hline \multirow{2}{*}{ Liver condition } & Cirrhosis & 69 & 67.6 \\
\hline & Chronic hepatitis & 33 & 32.4 \\
\hline \multirow{2}{*}{ Complete tumor capsule } & Present & 55 & 53.9 \\
\hline & Absent & 47 & 46.1 \\
\hline \multirow{4}{*}{ HCC grade } & $\square$ & 1 & 1.0 \\
\hline & $\square$ & 17 & 16.6 \\
\hline & Q & 83 & 81.4 \\
\hline & 表 & 1 & 1.0 \\
\hline \multirow{2}{*}{ Microvascular involvement } & Yes & 28 & 27.5 \\
\hline & No & 74 & 72.5 \\
\hline \multirow{2}{*}{ IM or MO group } & IM & 57 & 55.9 \\
\hline & MO & 45 & 44.1 \\
\hline \multirow{3}{*}{$\begin{array}{l}\text { Recurrence one month after } \\
\text { surgery }\end{array}$} & \begin{tabular}{|l|} 
Single \\
\end{tabular} & 22 & 21.6 \\
\hline & Multiple & 21 & 20.6 \\
\hline & None & 59 & 57.8 \\
\hline
\end{tabular}

Note: HBV: hepatitis B virus; HCV: hepatitis C virus; HCC: hepatocellular carcinoma; AFP: alph-fetoprotein; IM: intrahepatic metastasis; MO: multicentric occurrence; \&: Edmondson-Steiner grading.

Table-II: The comparison of clinicopathological features among single, multiple and none recurrence

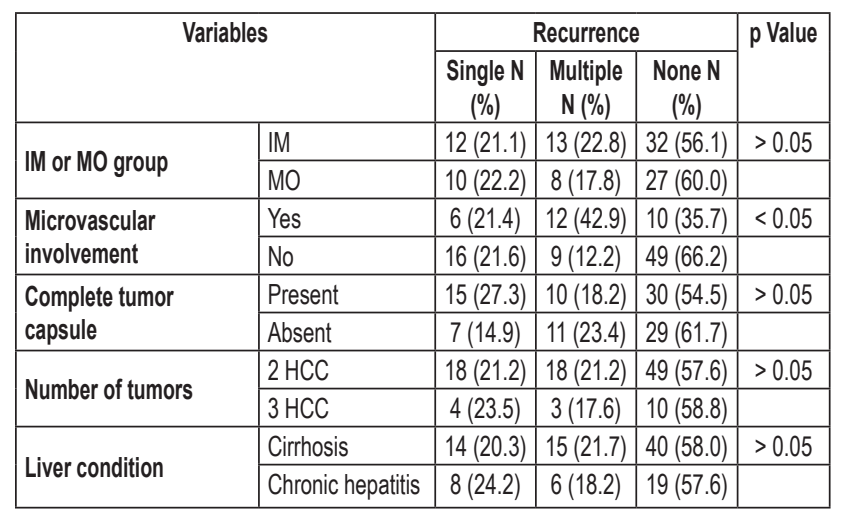

Note: IM: intrahepatic metastasis; MO: multicentric occurrence.

\section{Discussion}

Recent advances in liver resection techniques and perioperative management have enable the aggressive surgical intervention for patients with advanced liver cancer such as multinodular HCC. Several authors have proposed hepatic resection in selected groups of patients for multiple HCC demonstrating encouraging results ${ }^{13}$. However, whether hepatic resection is always appropriate for patients who have oligonodular HCCs is not clear, as the lesions may contain IM that lessen the therapeutic efficacy. A more recent study reported by Ruzzenente et $\mathrm{al}^{11}$ making an observation of 464 patient with advanced HCC. They applied a routine intraoperative ultrasonography to evaluated the presence of additional tumors and concluded that patients with oligonodular HCC could benefit from liver resection where survival is longer than after local ablative therapies (LAT) or supportive therapy (ST), but in patients with more than three HCCs, liver resection have similar results of LAT. Thus, how to identify the actual number of tumors before surgery become the key point for patients with oligonodular HCCs. As we know, HCC is diagnosed mainly by imaging techniques such as ultrasonography (US), computed tomography (CT) and magnetic resonance imaging (MRI). Although advances in imaging techniques have enable the detection of small $\mathrm{HCC}^{14-16}$, some small HCC nodules still can not be detected ${ }^{17}$. Moreover, HCCs often $\mathrm{MO}$ and are frequently accompanied by $\mathrm{IM}^{12,18,19}$. Therefore, hepatic surgons will face a puzzle to make a decision of surgery or LAT for patients with two or three tumor nodules.

The present study observed that $42.2 \%$ patients had tumour one month after surgery where $21.6 \%$ and $20.6 \%$ were defined as single and multiple recurrence respectively. Early recurrence is defined as intrahepatic, regional or systemic recurrence within 1 year. For these patients had recurrence within 1 month, we would like to name it very early recurrence or consider the prior surgery not a curative resection. The disappointing thing of this study is that there is no data of long-term survival at the present time, so we can not concluded that these patients could not benefit from hepatectomy arbitrarily. However, it has been reported that early recurrence after curative resection, is one of the most important 
factors impacting the prognosis and outcome of the disease. Recurrent disease has been found to be the leading cause of death during the first year ${ }^{20}$. Thus, we proposed that these patients would have a poor prognosis, regardless of very early recurrence or not a curative resection and the long-term survival will be reported in the further studies when we finish the follow-up.

There were $27.5 \%$ patients manifestated as microvascular involvement while other $72.5 \%$ patients were not. Further analysis demonstrated that microvascular involvement or not was significantly different among the three groups of recurrence, while there was no significant difference between IM and MO. Some groups have reported the incidence of $\mathrm{MO}$ in patients with $\mathrm{HCC}$ related to HCV reaches approximately $50 \%$, and $\mathrm{HCC}$ with IM recurs earlier and has a poorer prognosis than its MO counterpart ${ }^{21,22}$. Nevertheless, the discrimination of IM and $\mathrm{MO}$ in the above studies depended on the histopathologic examination. In fact, by clonal analysis using Southern blot hybridization, Hsu et al, found unicentric origin IM in 93.8\% patients with multiple HCCs that were histologically regarded as multicentric in origin ${ }^{23}$. This mean that most of the patients with multiple HCCs may be regarded as having IM, and multicentric HCCs with synchronous occurrence are thought to be clinically less important than those with metachronous ocurrence ${ }^{12}$. Without survival analysis, we could not estimate the differences of long-term prognosis between IM and MO, further study will be carried out to disclose the doubt.

\section{Conclusion}

The present study observed a high rate of very early recurrence for patients with oligonodular HCC just three months after hepatectomy. However, the hepatic resection seems no-account for these patients regardless which is true. Furthermore, the recurrence rate of patients with microvascular involvement was significantly higher than those without microvascular involvement, and there was no significant difference of recurrence between IM and $\mathrm{MO}$.

\section{References}

1. Parkin DM, Bray F, Ferlay J et al. Estimating the world cancer burden: Globocan 2000. Int J Cancer 2001; 94(2):153-6.

2. Hao XS, Wang PP, Chen KX, et al. Twenty-year trends of primary liver cancer incidence rates in an urban Chinese population. Eur $\mathrm{J}$ Cancer Prev 2003; 12:273-9.

3. Fan ST, Lo CM, Liu CL, et al. Hepatectomy for hepatocellular carcinoma: toward zero hospital death. Ann Surg 1999; 229:322-30.

4. Torzilli G, Makuuchi M, Inoue $\mathrm{K}$ et al. No-mortality liver resection for hepatocellular carcinoma in cirrhotic and non-cirrhotic patients: is there a way? A prospective analysis of our approach. Arch Surg 1999; 134:984-92.

5. Fong $Y$, Sun $R L$, Jarnagin $W$ et al. An analysis of 412 cases of hepatocellular carcinoma at a Western center. Ann Surg 1999; 229:790-9.

6. Llovet JM, Fuster JM, Bruix J. Intention-to-treat analysis of surgical treatment for early hepatocellular carcinoma: Resection versus transplantation. Hepatology 1999; 30:1434-40.
7. Yamamoto J, Okada S, Shimada K et al. Treatment strategy for small hepatocellular carcinoma: Comparison of long-term results after percutaneous ethanol injection therapy and surgical resection. Hepatology 2001; 34:707-13.

8. Tung-Ping Poon R, Fan ST, Wong J. Risk factors, prevention, and management of postoperative recurrence after resection of hepatocellular carcinoma. Ann Surg 2000; 232:10-24.

9. Shimada M, Takenaka K, Gion T et al. Prognosis of recurrent hepatocellular carcinoma: A 10-year surgical experience in Japan. Gastroenterology, 1996; 111:720-6.

10. Ikai I, Arii S, Okazaki M, et al. Report of the 17th Nationwide Follow-up Survey of Primary Liver Cancer in Japan. Hepatol Res, 2007; 37(9):676-91.

11. Ruzzenente A, Capra F, Pachera S et al. Is Liver Resection Justified in Advanced Hepatocellular Carcinoma? Results of an Observational Study in 464 Patients. J Gastrointest Surg 2009; 13:1313-20.

12. Matsumoto $Y$, Fujii $H$, Matsuda $M$ et al. Multicentric occurrence of hepatocellular carcinoma: diagnosis and clinical significance. J Hepatobiliary Pancreat Surg, 2001; 8:435-40.

13. $\mathrm{Ng} \mathrm{KK}$, Vauthey JN, Pawlik TM et al. Is hepatic resection for large or multinodular hepatocellular carcinoma justified? Results from a multiinstitutional database. Ann Surg Oncol, 2005; 12(5):364-73.

14. De Ledinghen V, Laharie $D$, Lecesne $R$ et al. Detection of nodules in liver cirrhosis: spiral computed tomography or magnetic resonance imaging? A prospective study of 88 nodules in 34 patients. Eur $\mathrm{J}$ Gastroenterol Hepatol 2002; 14:159-65.

15. Zacherl J, Pokieser P, Wrba F et al. Accuracy of multiphasic helical computed tomography and intraoperative sonography in patients undergoing orthotopic liver transplantation for hepatoma: What is the truth? Ann Surg 2002; 235:528-32.

16. Muramatsu $\mathrm{Y}$, Nawano S, Takayasu $\mathrm{K}$ et al. Early hepatocellular carcinoma: MR imaging. Radiology 1992; 182:161-5.

17. Tanaka Y, Sasaki Y, Katayama K et al. Probability of hepatocellular carcinoma of small hepatocellular nodules undetectable by computed tomography during arterial portography. Hepatology 2000; 31:890-8.

18. Ariizumi S, Takasaki K, Yamamoto M et al. Multicentric hepatocellular carcinoma tend to grow in more damaged segments of the liver. J Gastroenterol 2000; 35:441-4.

19. Ko $S$, Nakajima $Y$, Kanehiro $H$ et al. Significant influence of accompanying chronic hepatitis status on recurrence of hepatocellular carcinoma after hepatectomy. Ann Surg 1996; 224:591-5.

20. Regimbeau JM, Abdalla EK, Vauthey JN et al. Risk factors for early death due to recurrence after liver resection for hepatocellular carcinoma: Results of a multicenter study. J Surg Oncol 2004; 85:36-41.

21. Arii S, Monden K, Niwano M et al. results of surgical treatment for recurrent hepatocellular carcinoma: comparison of outcome among patients with multicentric carcinogenesis, intrahepatic metastasis, and extrahepatic recurrence. J Hepatobiliary Pancreat Surg 1998; 5:86-92.

22. Horigome $\mathrm{H}$, Nomura $\mathrm{T}$, Nakao $\mathrm{H}$ et al. Treatment of solitary small hepatocellular carcinoma: consideration of hepatic functional reserve and mode of recurrence. Hepatogastroenterology 2000; 47:507-11.

23. Hsu HC, Chiou TJ, Chen JY et al. Clonality and evolution of hepatocellular carcinoma with multiple nodules. Hepatology 1991; 13:923-8. 